\title{
UMA ANÁLISE CRÍTICA ACERCA DA POSSIBILIDADE DE REDUÇÃO DA IMPUTABILIDADE PENAL NO DIREITO BRASILEIRO
}

\section{A CRITICAL ANALYSIS ON THE POSSIBILITY OF REDUCTION OF CRIMINAL IMPUTABILITY IN BRAZILIAN LAW}

\author{
Bianca Tito ${ }^{1}$ \\ Bibiana Terra ${ }^{2}$
}

Resumo: A pesquisa propõe, a partir da Constituição Federal Brasileira de 1988 e de legislação pertinente, uma análise da legitimidade na redução da imputabilidade penal, hoje fixada aos 18 anos. Para tanto, analisa princípios e normas, dentre os quais a proteção integral de crianças e adolescentes, a prioridade absoluta, o Estatuto da Criança e do Adolescente, a Constituição brasileira, o Código Penal, e outros. Da mesma forma, em perspectiva teórica, procura apontar e analisar alguns dos principais argumentos que surgem dentro das discussões sobre a redução da imputabilidade penal no Brasil. O objetivo geral do trabalho é verificar se a redução da imputabilidade penal violaria os mencionados princípios e, igualmente, seria uma violação do sistema constitucional que atualmente vigora no Brasil. Essa se constitui em uma pesquisa de grande relevância e que é sempre atual no cenário brasileiro, dadas as influências políticas e sociais que a temática envolve, podendo, portanto, contribuir tanto para os estudos em Direito, notadamente em Direito Penal e Constitucional, mas, também, em um viés social, que levanta discussões dentro da sociedade brasileira. Para realizá-la, adota como metodologia a de revisão bibliográfica, utilizando de fontes consideradas necessárias ao desenvolvimento da pesquisa proposta, a qual tem caráter descritivo e explicativo. Diante de tal análise, conclui-se que a redução da imputabilidade penal caminha em sentido contrário ao que hoje prevê a legislação brasileira, segundo a qual deve prevalecer a proteção de crianças e adolescentes, pois que os direitos garantidos a esses sujeitos não poderão ser alterados de forma a prejudicá-los.

Palavras-chave: Imputabilidade Penal. Maioridade Penal. Melhor interesse da criança e do adolescente. Direito Constitucional. Democracia.

Abstract: Based on the Brazilian Federal Constitution of 1988, and in relevant legislation, this research proposes an analysis of the legitimacy of reducing criminal liability, currently set at 18 years of age. For that, it analyzes principles and norms, among which the integral protection of children and adolescents, the absolute priority, the Statute of the Child and the Adolescent, the Brazilian Constitution, the

\footnotetext{
${ }^{1}$ Mestra em Direito, com ênfase em Constitucionalismo e Democracia, na Linha de Pesquisa Efetividade dos Direitos Fundamentais Sociais, pela Faculdade de Direito do Sul de Minas - FDSM. Autora da obra "O direito à liberdade de expressão: o humor no Estado Democrático de Direito" e organizadora da obra "Direito e Democracia: a liberdade de expressão no ordenamento jurídico brasileiro", no qual também é co-autora de um dos capítulos. Especialista em Direito de Família e das Sucessões pela Universidade Anhanguera-Uniderp.

${ }^{2}$ Mestra em Direito, com ênfase em Constitucionalismo e Democracia, na Linha de Pesquisa Relações Sociais e Democracia, pela Faculdade de Direito do Sul de Minas (FDSM). Especialista em Direito Internacional pela Escola Brasileira de Direito - EBRADI.
}

Revista Auditorium, Rio de Janeiro, v. 25, n. 52, p. 36-61, jul./out. 2021 
Penal Code, and others. From a theoretical perspective, it seeks to point out and analyze some of the main arguments that arise within the discussions on the reduction of criminal liability in Brazil. The general objective of the work is to verify whether the reduction of criminal liability would violate the aforementioned principles and so would be a violation of the constitutional system currently in force in Brazil. This constitutes a research of great relevance and is always current in the Brazilian scenario, given the political and social influences that the theme involves, and can therefore contribute so much to studies in Law, notably in criminal and constitutional law, but, also, in a social perspective, which raises discussions within Brazilian society. To carry it out, it adopts the methodology of literature review, using sources considered necessary for the development of the proposed research, which has a descriptive and explanatory character. In view of this analysis, it is concluded that the reduction of criminal liability goes in the opposite direction to what is currently provided by Brazilian legislation, according to which the protection of children and adolescents must prevail, since the rights guaranteed to these subjects cannot be changed in order to harm them.

Keywords: Criminal liability. Criminal majority. Best interests of children and adolescents. Constitutional Law. Democracy.

Recebido em: 30/07/2021 Aceito para publicação em: 07/10/2021 


\section{INTRODUÇÃo}

O objetivo geral desta pesquisa é verificar se a redução da imputabilidade penal viola o texto constitucional brasileiro e demais legislações nacionais, como, por exemplo, o Estatuto da Criança e do Adolescente - ECA (Lei no 8.069 de 13 de julho de 1990), que prevê princípios como o do melhor interesse da criança e do adolescente, que não pode ser ignorado em uma discussão como essa. Para isso, traz um problema de pesquisa que foi estruturado com a finalidade de questionar se no contexto brasileiro, e em observância do sistema constitucional atualmente vigente no país, eventual redução da imputabilidade penal se constituiria em uma prática revestida de legitimidade.

Dessa forma, aborda a possibilidade de que a imputabilidade penal venha a ser reduzida no Brasil, fazendo, especialmente, uma leitura dessa questão à luz da Constituição Federal de 1988. Não obstante, para não ficarmos tão somente em uma análise legislativa, ainda que essa seja muito importante e por si só nos possibilite um trabalho de grande relevância, o presente artigo se preocupa também em apresentar uma contextualização teórica do tema. Com isso, nos propomos a descrever e analisar alguns dos principais argumentos levantados pelas discussões sobre essa temática no cenário brasileiro. De maneira que a partir deles possamos testar as nossas hipóteses e alcançarmos uma resposta para o problema de pesquisa que norteia a presente investigação.

Em relação a isso, vale destacar que essa é uma discussão de bastante divergência entre os autores brasileiros, bem como em cenário internacional, embora esse não seja o âmbito de nossa pesquisa, que faz um recorte no contexto nacional, mostra-se que um dos principais pontos dentro dessa temática é o de buscar compreender se a imputabilidade penal se constitui ou não em uma cláusula pétrea. Isso é importante para a nossa pesquisa porque refere-se justamente a um desdobramento da legitimidade de tal redução, que é o foco desta. E, sendo assim, as hipóteses aqui apresentadas e testadas são duas: I) a imputabilidade penal não se constitui em uma cláusula pétrea e, portanto, é legitimamente possível a sua alteração; II) medida nesse sentido coloca em risco a proteção garantida aos 
adolescentes, proteção essa que possui fulcro constitucional e, assim, violaria preceitos constitucionais.

Para testá-las é realizada uma pesquisa que possui caráter tanto descritivo, como também explicativo. Isso porque a nossa pretensão é não só de apresentarmos uma contextualização, legislativa e teórica, da presente temática, apontando os principais pontos que a envolvem, mas igualmente de, a partir disso, construímos uma explicação que nos auxilie a trazermos alguma resposta para o problema de pesquisa que foi levantado. Dessa maneira, a pesquisa descritiva e explicativa se faz a mais pertinente. Ainda, quanto aos procedimentos técnicos utilizados, adota-se a metodologia bibliográfica, utilizando-nos, enquanto fontes de pesquisa, de materiais que já se encontram previamente elaborados, como livros e artigos científicos de publicação periódica. Além disso, fazemos uso de legislações compreendidas como relevantes, com uma análise documental delas.

Tendo em vista o nosso objetivo geral, tem-se como objetivo específico explicar o contexto da imputabilidade penal na história brasileira, de forma a demonstrar a atual realidade que envolve o debate acerca da sua potencial redução, além de demais conceitos e outros aspectos que the dizem respeito. Por essa razão, encontra-se estruturada em 3 seções: I) na primeira é feita uma análise da culpabilidade, dado que essa traz dentre os seus elementos a imputabilidade e, logo, o seu estudo nos auxilia a alcançarmos uma melhor compreensão do tema; II) em um segundo momento, há uma abordagem histórica da imputabilidade penal desde o seu surgimento no ordenamento jurídico brasileiro, com a descrição de seu conceito e análise de suas características e principais princípios que a envolvem; III) Por fim, na última seção, são descritos e analisados os diferentes argumentos sobre uma possível redução da imputabilidade penal, buscando uma compreensão de qual delas melhor responde o nosso problema de pesquisa.

Esse se constitui em um estudo de grande relevância para as áreas do Direito Penal e, de igual modo, do Processo Penal brasileiro, pois refere-se a um tema que causa bastante divergência dentro de nossa doutrina nacional. Além disso, é uma questão que gera profundas discussões e polêmicas na sociedade de modo geral, posto que os cidadãos igualmente se veem desejosos de participarem do debate e 
apresentarem as suas próprias noções sobre o assunto. Dessa maneira, o espaço democrático do ambiente acadêmico, com pesquisas responsavelmente realizadas, tem muito a contribuir em tais debates, apresentando considerações que possuem um embasamento teórico e legislativo, afastadas de particularismos e opiniões pessoais, mas de cunho científico.

\section{A CULPABILIDADE COMO CONCEITO ANALÍTICO DE CRIME}

A culpabilidade é um elemento integrante do conceito de crime, tendo como intuito analisar se o agente da conduta ilícita é penalmente culpável, ou seja, se ele agiu com dolo ou com negligência, imprudência ou imperícia, em qualquer uma dessas modalidades ${ }^{3}$. Ela destaca-se como um dos pontos centrais da ciência jurídico-penal, pois serve como forma de fundamentar o castigo estatal. Um dos sentidos de seu conceito a determina como fundamento da pena, porquanto parte da análise de ser ou não possível a aplicação da pena àquele que pratica um fato típico e antijurídico, ou seja, que é proibido pela lei penal.

No entanto, para tanto, alguns requisitos são exigidos, como a capacidade de culpabilidade, a potencial consciência da ilicitude e a exigibilidade de conduta diversa, os quais são elementos positivos específicos do conceito dogmático de culpabilidade. De modo que a ausência de qualquer um deles basta para impedir a aplicação da sanção penal, isto é, há uma excludente de culpabilidade (BITENCOURT, 2007). Assim, o conceito normativo da culpabilidade tem como fundamento a capacidade do agente em saber controlar suas ações perante seu conhecimento

\footnotetext{
3 O dolo trata-se da intenção, a vontade livre e consciente do agente em praticar a conduta antijurídica para obter o resultado. Já na negligência, a pessoa deixa de tomar uma atitude ou apresentar conduta que era esperada para a situação. Age com descuido, indiferença ou desatenção, não tomando as devidas precauções. Implica em o agente deixar de fazer algo que sabidamente deveria ter feito, dando causa ao resultado danoso. A imprudência, por sua vez, pressupõe uma ação precipitada e sem cautela. A pessoa não deixa de fazer algo, não é uma conduta omissiva como a negligência. Nesta ela age, mas toma uma atitude diversa da esperada. Para que seja configurada a imperícia é necessário constatar a inaptidão, ignorância, falta de qualificação técnica, teórica ou prática, ou ausência de conhecimentos elementares e básicos da profissão.

Revista Auditorium, Rio de Janeiro, v. 25, n. 52, p. 36-61, jul./out. 2021
} 
concreto de saber o que realmente faz e na exigibilidade de conduta diversa ${ }^{4}$ (SANTOS, 2012).

Tais elementos se justificam no entendimento de ser o Direito Penal possuidor de função ético-social à proteção dos bens jurídicos considerados essenciais à vida em comum no meio social. Por isso, cabe a esse a tarefa exclusiva de proteger os bens jurídicos frente às condutas que os lesionem e os coloquem em perigo. Para cumprir esse papel são impostas à coletividade, por meio do legislador, normas penais incriminadoras, as quais podem ser proibitivas ou mandamentais. Acerca da culpabilidade, historicamente, essa sempre esteve conectada ao dolo e à culpa. Porém, com o advento de seu conceito normativo, de modo majoritário, a doutrina não mais entende que tais elementos sejam os que a compõem (COSTA, 2016).

Sobre isso, primeiramente, deve ser destacado que havia uma concepção clássica para a culpabilidade, a qual já foi superada, e que tratava da relação entre a vontade do autor e de seu ato, o que significa dizer que para que o agente fosse reconhecido como culpado precisaria ter cometido uma falta e, então, merecer reprovação. No entanto, em uma concepção como essa, há a ideia da culpabilidade moral, que não mais se relaciona com a Justiça Penal, já que esta, agora, diz respeito apenas à própria pessoa (BONCHRISTIANO, 2002). Criticada tal interpretação, acabou por surgir posteriormente uma nova, a qual se constitui como puramente normativa do finalismo e, assim, os elementos subjetivos da culpabilidade (o dolo e o dever objetivo de cuidado) foram superados ${ }^{5}$ e passaram a integrar a ação e não mais a culpabilidade (OLIVEIRA, 2014). Ainda assim, salienta-se que não há na teoria do Direito Penal uma conceituação unânime acerca da culpabilidade.

\footnotetext{
${ }^{4}$ Isso significa que são elementos da culpabilidade: a imputabilidade - capacidade de responder penalmente pelos atos ilícitos que pratica -; a exigibilidade de conduta diversa - é a razoável possibilidade de se comportar em conformidade ao direito -; e, ainda, a potencial consciência de ilicitude - possibilidade de obter conhecimento e informação de que a ação ou omissão de determinado fato é ilícito e, portanto, contrário ao direito (SANTOS, 2012, p. 275).

${ }^{5}$ No direito penal, atualmente, a culpabilidade é admitida desde que não esteja relacionada à consciência da pessoa, mas sim com a pena. O que se reprova, portanto, é o ato realizado e não a atitude interna, assim, o que é penalmente culpável é o atentado praticado contra os valores que são protegidos por lei e sob os quais descansa a sociedade. Neste sentido, não é possível falar na existência da culpabilidade em si mesma, mas tão somente em uma culpabilidade em decorrência do fato antijurídico, devendo o exame da culpabilidade do agente apenas ser realizado após a comprovação da ocorrência de um fato que seja estabelecido como antijurídico (BONCHRISTIANO, 2002).

Revista Auditorium, Rio de Janeiro, v. 25, n. 52, p. 36-61, jul./out. 2021
} 
O conceito normativo de culpabilidade está previsto no ordenamento jurídico brasileiro desde 1984, quando houve a reforma do Código Penal. Um dos seus elementos a ser analisado é a capacidade de culpabilidade ou imputabilidade, considerada um atributo que se faz necessário para a compreensão da natureza proibitiva de algumas ações e como forma de orientar o comportamento mediante esse entendimento, é, então, um atributo jurídico dos indivíduos que possuem determinados níveis de desenvolvimento biológico e de normalidade psíquica (COSTA, 2016).

Logo, a culpabilidade é entendida como um elemento central para a imputação, sendo, por este motivo, indispensável. Desta forma, não há como falarmos em Direito Penal separado da culpabilidade (OLIVEIRA, 2014). O poder punitivo do Estado está diretamente relacionado à culpabilidade, sendo esta, inclusive, uma de suas limitadoras, juntamente ao princípio da legalidade ou reserva legal e ao princípio da intervenção mínima. Se na realização do exame dos fatos não conseguir ser constatado que a ação é típica, será desnecessário verificar se ela é antijurídica e culpável. Isso porque cada uma dessas características possui critérios valorativos próprios, os quais também possuem efeitos teóricos e práticos próprios (BITENCOURT, 2007).

Abordado, ainda que brevemente, o conceito de culpabilidade, somos agora capazes de nos debruçarmos sobre um de seus elementos, que é o que interessa a presente pesquisa: a imputabilidade penal ${ }^{6}$. Em relação a isso, como vimos, os elementos da culpabilidade são exigidos no preenchimento da conduta, pois compõem os seus elementos positivos específicos. Se constituindo no terceiro elemento da culpabilidade e sendo, também, fundamento do castigo estatal, a imputabilidade penal é um requisito para a aplicação da sanção penal, de maneira que aquele que não a possuir não poderá ser declarado culpado, isto é, não sendo responsabilizado pelos seus atos, ainda que eles sejam típicos e antijurídicos (MINAHIM, 2004).

\footnotetext{
${ }^{6}$ Embora a consciência da ilicitude e a exigibilidade de conduta diversa também façam parte dos elementos que compõe a culpabilidade, tendo em vista o objetivo da pesquisa, optamos por abordar especificamente o seu terceiro elemento, referente a imputabilidade penal, objeto de nossa análise. Revista Auditorium, Rio de Janeiro, v. 25, n. 52, p. 36-61, jul./out. 2021
} 
A imputação provém do termo imputabilidade, significando a aptidão de ser culpável, de acordo com a teoria da imputabilidade moral (livre arbítrio) (BARBATO JÚNIOR, 2004). Em sentido bastante amplo, a imputabilidade é a possibilidade de ser um ato culpável atribuído a alguém, é a capacidade de obrar criminosamente. De maneira que aqueles que não possuem tal capacidade não poderão ser declarados culpados, o que acarreta em não poderem ser penalmente responsabilizados por seus atos. Essa não se confunde com a responsabilidade, a qual é um princípio pelo qual o imputável (pessoa dotada da capacidade de culpabilidade) deve responder por suas ações (BITENCOURT, 2007). O Código Penal brasileiro não traz em seu texto uma definição para a imputabilidade penal, a não ser através da exclusão, quando estabelece as causas que a afastam.

No ordenamento jurídico brasileiro a imputabilidade é expressamente excluída em determinadas hipóteses, quais sejam: em caso de doença mental ou desenvolvimento mental incompleto ou retardado, conforme previsão do art. 26 do Código Penal; na embriaguez acidental completa, conforme $\S 1^{\circ}$ do art. 28; e a menoridade, prevista pelo art. 27. Em relação a essa última, entende-se que são adultos dotados de culpabilidade os maiores de 18 anos, estando, portanto, sujeitos às sanções definidas pelo Direito Penal.

Ao passo que crianças e adolescentes, menores de 18 anos, são submetidos a normas específicas, tendo em vista sua condição peculiar de pessoa em desenvolvimento ${ }^{7}$. Isso significa que, para os menores, é adotado um sistema de responsabilização voltado a essa classe específica. Acerca dessa menoridade, portanto, a imputabilidade, por presunção legal, inicia-se aos 18 anos. 0 que se dá porque a legislação brasileira optou por seguir o sistema biológico ${ }^{8}$ na definição da chamada "maioridade penal". Considerada então como inimputável o menor que essa idade, de forma a ignorar o seu desenvolvimento mental, ainda que já possua plena capacidade de compreender a ilicitude do fato (BITENCOURT, 2007).

\footnotetext{
${ }^{7}$ De acordo com o que dispõe o art. $2^{\circ}$ do Estatuto da Criança e do Adolescente (Lei 8.069/90), são considerados crianças aqueles com até doze anos de idade incompletos, e como adolescentes as pessoas entre doze e dezoito anos de idade.

${ }^{8}$ Com base neste, é observada exclusivamente a característica física do agente, independentemente de sua capacidade psicológica, sendo observada tão somente a idade cronológica, exclusivamente contada em anos, independentemente da capacidade mental.

Revista Auditorium, Rio de Janeiro, v. 25, n. 52, p. 36-61, jul./out. 2021
} 
Cumpre destacar, acerca disso, que foram razões de política criminal que levaram o legislador brasileiro a optar pela presunção absoluta de inimputabilidade do menor de 18 anos, fato esse que a própria exposição de motivos do Código Penal de 1940 justifica. Não obstante, essa escolha continua até hoje gerando inúmeras discussões, como, por exemplo, a possibilidade de redução da imputabilidade penal, e se seria essa uma medida legítima ou não. Residindo sobre essa o objetivo de nossa pesquisa, na sequência é abordada a história da imputabilidade penal na legislação brasileira e os princípios que a norteiam, de modo que isso possa nos fornecer o embasamento teórico necessário para encontrarmos alguma resposta ao problema de pesquisa.

\section{A IMPUTABILIDADE PENAL NA LEGISLAÇÃO BRASILEIRA}

A inimputabilidade penal está prevista na Constituição Federal de 1988 através de seu art. 228, segundo o qual os menores de 18 anos são considerados penalmente inimputáveis, estando, portanto, sujeitos a legislação especial. Em mesmo sentido, há previsão no art. 27 do Código Penal, que já determina sobre a questão, tendo o texto constitucional de 88 confirmado tal garantia através de seu Capítulo VII, que trata da família, da criança, do adolescente, do jovem e do idoso. Isso significa que ela é uma garantia dada a esses indivíduos de que enquanto não completarem a maioridade não responderão criminalmente como adultos e não serão, então, responsabilizados com base no que estabelece o Código Penal brasileiro.

Ainda no que se refere a Constituição brasileira, o art. 227 estabelece ser dever da família, da sociedade e do Estado, conjuntamente, assegurarem com absoluta prioridade o direito à vida, saúde, alimentação, educação, dignidade, entre outros direitos, as crianças, adolescentes e jovens, colocando-os a salvo de toda forma de negligência, violência ou crueldade que possam vir a ser submetidos. Assim, de um ponto de vista histórico, nota-se que na legislação brasileira a idade é grande influenciadora no elemento jurídico do crime, a culpabilidade. De forma que se o agente do fato típico e ilícito for menor de 18 anos, então essa não estará 
presente, pois falta um dos elementos necessários para sua configuração, qual seja, a imputabilidade.

No entanto, a adoção do critério biológico na fixação da idade mínima não foi um entendimento pacífico na evolução das leis penais brasileiras. Quanto a isso, em 1831, com o advento do Código Criminal do Império, sancionado por Dom Pedro I, teve início a fase nacional de aplicação de leis criminais no Brasil-Império. Esse código estabelecia através de seu art. $10^{\circ}$ que não seriam julgados criminosos os menores de 14 anos, mas sim considerados inimputáveis, adotando, portanto, o critério biológico na fixação da idade-limite da capacidade penal. O legislador do Império ainda se manifestou quanto aos menores de 14 anos que agissem com discernimento, estabelecendo medidas que seriam aplicadas a eles e demonstrando, nesses casos, adotar um critério duplo, biopsicológico.

Neste, são observadas tanto as características físicas do agente, como a sua capacidade de entender. Ou seja, observam-se condições puramente físicas do agente, mas também as suas características psicológicas de discernimento sobre os atos cometidos. $O$ seu art. 13 previa que se houvesse o menor obrado com discernimento, então poderia vir a ser recolhido em casas de correção até os seus 17 anos. Porém, cumpre destacar que interpretação nesse sentido se revela, para alguns autores, bastante problemática, pois a referida "capacidade de discernimento" presente no art. 13 viria a abrir caminho para a ocorrência de muitos abusos, dando lugar a mais um doloroso espetáculo, pois no que se refere ao discernimento apenas, é possível que esse seja notado até mesmo em uma criança de cinco anos (BARRETO, 1926).

Ocorrida a proclamação da República em 1889, foi criada uma comissão para elaborar o novo código criminal, o qual entrou em vigência em outubro de 1890 e que, em seu texto, optou por continuar a adotar a Teoria do Discernimento. Esse determinava como inimputáveis os menores de 9 anos e os que, maiores de 9 e menores de 14 anos, agissem sem discernimento. Aqueles que a demonstrassem em suas ações poderia ser aplicada uma sanção de recolhimento em estabelecimentos disciplinares industriais, por tempo fixado pelo juiz e que não ultrapassasse os 17 anos do agente (MARANHÃO; GOMES, 2007). 
Isso significa que apenas os menores de 9 anos estavam totalmente livres das sanções penais, enquanto os de 9 anos completos aos 14 possuíam uma inimputabilidade condicionada, só não sendo considerado criminoso se deixasse claro ter agido sem discernimento (MASSA, 1993). Com isso, a consolidação das leis penais em 1932 pode ser considerada como o pontapé inicial da fixação da idade da imputabilidade penal em 18 anos, pois embora tenha mantido a inimputabilidade do menor em 14 anos, dispôs em seu art. 69 que o menor com idade compreendida entre 14 e 18 anos seria submetido a processo especial, podendo ser internado em escola de reforma pelo prazo mínimo de 3 anos e máximo de 7. Ainda, o art. 71 determinava que em relação àqueles com idade entre 16 e 18 anos, se praticassem crimes graves, poderiam ser punidos desde que sua pena jamais fosse cumprida na companhia de adultos (LOBO, 2008).

Já na atual legislação brasileira, o Código Penal de 1940 teve a sua Parte Geral reformada em 1984 (Lei 7.209/84). Com base nesse, conforme previsto pelo art. 27, os menores de 18 anos são penalmente inimputáveis, ficando sujeitos às normas estabelecidas em legislação especial. Em igual sentido, com o advento da Constituição Federal de 88 , foi pela primeira vez inserido em um texto constitucional brasileiro a idade como um fator determinante da imputabilidade penal. 0 que serviu para inviabilizar a realização de qualquer modificação desse critério sem que isso ocorresse por meio de Emenda Constitucional. Isso porque, caracterizada como um preceito constitucional, traz como consequência que a sua alteração só pode se dar através de um procedimento que seja também capaz de alterar o texto da Constituição, dada a necessidade de observância ao princípio da hierarquia das leis (LOBO, 2008).

Deste modo, tão somente a utilização de lei ordinária como forma de alterar o que prevê o art. 27 do Código Penal não terá efeito, vez que é também imprescindível a modificação constitucional. $O$ que demonstra a preocupação que teve a Subcomissão da Família, da Criança, do Jovem, do Adolescente e do Idoso, do legislador constituinte em geral, com uma possível diminuição neste limite de idade. Visaram, assim, dar maior proteção às crianças e adolescentes. De maneira que pela primeira vez na história das constituições brasileiras o problema da 
responsabilização dos menores foi tratado como uma questão pública. O que se revela bastante importante, dado que se passou a considerá-los como pessoas em desenvolvimento, sendo vistos como sujeitos de direitos. Por isso, os atos cometidos por menores são caracterizados como "ato infracional", em que após procedimento que dê a esses a oportunidade de defesa, poderão ser submetidos às medidas previstas pelo ECA.

Ainda, em relação aos princípios norteadores da imputabilidade, podemos destacar o da proteção integral de crianças e adolescentes, previsto tanto na Constituição Federal, como no Estatuto da Criança e do adolescente, em que, no caso desse último dispositivo, se localiza logo no art. $1^{0}$, de acordo com o qual a lei disporá a respeito de tal proteção, ensejando a segurança dos menores em todas as esferas de sua existência, seja física, intelectual, psicológica ou social. Bem como a sua promoção, sem realizar quaisquer distinções de classe social, origem, raça ou sexo. Esse princípio abarca uma corresponsabilidade, pois tanto a família, a comunidade, a sociedade e o Estado possuem parcela de responsabilidade em garantir para esses indivíduos os direitos fundamentais previstos constitucionalmente.

Igualmente, há o princípio da prioridade absoluta, que previsto pelo parágrafo único do art. $4^{\circ}$ do ECA, determina que essa deve compreender a preferência na formulação e execução das políticas sociais públicas e destinação privilegiada de recursos públicos para áreas que sejam relacionadas à proteção da infância e da juventude. Outro notável princípio é o do respeito à condição peculiar de pessoa em desenvolvimento, segundo o qual devem alguns critérios ser observados no momento de aplicar punição ao menor, não podendo deixar de observar também as características particulares desses sujeitos que ainda estão em seu desenvolvimento físico e mental. Esse princípio é responsável por reconhecer o adolescente como uma pessoa em desenvolvimento, motivo pelo qual o Estatuto da Criança e do Adolescente prevê medidas socioeducativas, além das de proteção.

Há também que se falar no melhor interesse da criança e do adolescente, pois havendo conflito de interesses, a preferência será dada aquilo que mais os beneficia, devendo os seus interesses prevalecerem. Interpretação essa que deriva 
de documentos internacionais que motivaram sua incorporação ao texto constitucional e ao Estatuto. O que vale não só para a questão específica da imputabilidade, mas em outros setores, como o divórcio e a adoção, por exemplo, dentre outras situações que envolvam o bem-estar infantojuvenil.

Os direitos de todas as crianças e adolescentes devem ser universalmente reconhecidos, pois com base em ordem constitucional estes são especiais e específicos, considerando-os pessoas em desenvolvimento e sendo essa uma condição peculiar que possuem (LIBERATI, 2006). Sobre isso, de modo breve, importa salientar que foi com a Declaração de Genebra, em 26 de março de 1924, que houve um "pontapé" inicial rumo à proteção especial, vez que essa previa a necessidade de ser proporcionada para crianças e adolescentes uma proteção especial, o que posteriormente veio a ser acolhido pela Declaração Universal dos Direitos Humanos - DUDH, proclamada pela Assembleia Geral das Nações Unidas em 1948.

Portanto, o Estado brasileiro reconhece que no tocante ao adolescente em conflito com a lei, será o ECA aplicado de forma a atribuir-lhe responsabilidade própria de sua condição, não deixando que a inimputabilidade penal seja confundida com impunidade. Nesse quesito, 0 Estatuto se baseia em um sistema de responsabilidade, com fundamentação em princípios garantistas e um sistema de direito penal juvenil, sob os fundamentos do direito penal mínimo, não se rendendo ao direito penal máximo e nem ao abolicionismo penal (SARAIVA, 2002). 


\section{REDUÇÃO DA IMPUTABILIDADE PENAL NO BRASIL: PODEMOS FALAR EM LEGITIMIDADE?}

Uma parcela da doutrina brasileira acredita que deve ser encontrada uma solução diferente para o problema dos jovens infratores, uma vez que a possibilidade de redução da imputabilidade penal, fixando-a abaixo dos dezoito anos, coloca em risco o princípio da proteção de crianças e adolescentes, garantido constitucionalmente. Buscam demonstrar que o princípio da proteção da criança e adolescente impõe limites materiais à redução da imputabilidade penal. Isso porque a norma constitucional reforçou o que já era estabelecido no art. 27 do Código Penal, sendo os direitos a inimputabilidade penal e da brevidade na privação de liberdade direitos individuais e, consequentemente, cláusulas pétreas ${ }^{9}$.

É necessário considerar o fato de que por meio de seu capítulo VII a Constituição brasileira tratou dos direitos da criança e do adolescente não apenas no que se refere ao âmbito penal, mas também em demais setores de suas vidas. O que demonstra a compreensão do legislador de que esses são sujeitos em desenvolvimento e, logo, detentores de uma proteção especial. Nesse contexto, a constitucionalização dos direitos da criança e do adolescente revela-se uma barreira às propostas de alteração do texto constitucional, posto que atitude nesse sentido coloca não só a imputabilidade penal em risco, mas também toda a ordem constitucional do país. Ou seja, segundo uma interpretação nesse sentido, existiria uma incompatibilidade sistêmica no rebaixamento da imputabilidade penal em face da Constituição de 88 (SPOSATO; MATOS, 2013).

Sendo um direito fundamental dos menores de 18 anos que sejam processados, julgados e sentenciados com base em legislação especial, diferenciada da que é aplicada aos adultos e que tem fundamentação no Código

\footnotetext{
${ }^{9}$ Essas são definidas como dispositivos constitucionais imutáveis, não podendo ser modificadas e nem excluídas. Também não poderá haver proposta de emenda constitucional ou medida provisória que de qualquer maneira as altere, independentemente de ter essa proposta origem no executivo ou no legislativo. Seu objetivo é impedir alterações nos direitos fundamentais dos cidadãos e que garantam a soberania da nação e seu regime democrático. Assim, para que esses aspectos sejam modificados será necessária uma nova constituição. São estabelecidas hoje como cláusulas pétreas aquelas previstas no art. $60, \S 4{ }^{\circ}$, incisos I a IV, da Constituição Federal, quais sejam: a forma federativa do Estado, o voto direto, secreto, universal e periódico, a separação dos poderes e os direitos e garantias individuais.
}

Revista Auditorium, Rio de Janeiro, v. 25, n. 52, p. 36-61, jul./out. 2021 
Penal. Não sendo indispensável que esteja expressamente previsto no rol do art. $5^{0}$ do texto constitucional para que seja considerado um direito ou garantia individual. Bastando estar neste previso como um direito ou garantia que trate diretamente do respeito à vida, liberdade ou igualdade, sendo, portanto, inviolável (SPOSATO; MATOS, 2013).

Em mesmo sentido, um outro argumento a adentrar nesta discussão é o de que tendo a Constituição fixado a imputabilidade penal (art. 228), essa é então uma garantia individual à disposição dos jovens. Consequentemente, referindo-se a uma cláusula pétrea, o que significa que, conforme estabelecido no art. 60, IV, ela não poderá ser objeto de deliberação para Proposta de Emenda Constitucional PEC. Isso demonstra que há uma compreensão segundo a qual o legislador constituinte, ao colocar a imputabilidade no texto constitucional sem se importar em localizá-la em lugar específico (como seria, por exemplo, no rol do art. 5a), mas apenas em defini-la como uma garantia individual, já a teria tomado como insuscetível de sofrer alteração através de Emenda Constitucional. Pois se assim não a compreendesse então teria deixado a questão apenas a cargo de legislação infraconstitucional, sem se preocupar em trazê-la para o texto constitucional (MARANHÃO; GOMES, 2007).

Ainda, em termos dos alegados benefícios sociais que poderiam ser trazidos pela redução da imputabilidade penal (há aqueles que alegam que os menores se beneficiam dessa para a prática de atos ilícitos e que a redução diminuiria tais ocorrências ${ }^{10}$ ), há quem critique tal interpretação, pois entenderam que essa na verdade representaria um ataque ao Estado Democrático de Direito, sendo inconstitucional. Isso porque faria com que jovens fossem deixados a mercê de criminosos adultos, submetidos a tratamento desumano, sem levar em

\footnotetext{
10 Parcela da sociedade brasileira é levada a acreditar que a redução da idade hoje fixada para a imputabilidade penal trará muito mais benefícios do que prejuízos, significando uma solução para o combate à criminalidade. Além disso, um dos argumentos mais utilizados pelos defensores da redução da imputabilidade penal é o de que estes menores são inseridos na prática de crimes por aqueles que já possuem idade suficiente para serem responsabilizados como adultos, pois acreditam que o menor sairá impune ou, tendo alguma punição, essa será branda demais se comparada a que é aplicada aos maiores. No entanto, faz-se necessário entender que a imputabilidade penal não é sinônimo de impunidade, pois aos menores será aplicada medida socioeducativa, podendo essa incluir até mesmo a privação de sua liberdade. Ou seja, eles não se encontram livres de toda e qualquer punição (SARAIVA, 1997).

Revista Auditorium, Rio de Janeiro, v. 25, n. 52, p. 36-61, jul./out. 2021
} 
consideração as suas características individuais, em que se encontram em fase de desenvolvimento físico e mental (GRAU; TELLES JÚNIOR, 2001).

Um argumento a compor as discussões sobre a possibilidade de ter a imputabilidade penal reduzida é aquele que diz respeito ao direito ao voto. Isso se dá porque no Brasil esse é um direito que passa a poder ser exercido a partir dos 16 anos, em que entre os 16 e 18 se dá de modo facultativo e não obrigatório. Porém, para alguns autores, um argumento nesse sentido deve ser considerado irrelevante, dado que, primeiramente, é facultativo, e, segundo, porque votar em pleitos eleitorais é bastante diferente de ter uma sanção penal Ihe sendo aplicada, com a possibilidade de restrição da sua liberdade. A imputabilidade penal é compulsória e não facultativa (SARAIVA, 1997).

A prática de um crime é ato jurídico completamente diverso, possuindo maior particularidade entre os atos jurídicos que uma pessoa pode praticar. A capacidade para a vida social e suas responsabilidades é alcançada em diferentes fases da vida da pessoa. Evidente que muitos adolescentes de 16 e 17 anos já possuem capacidade de discernimento, no entanto isso não poderia por si só constituir-se em uma justificativa suficiente. Até mesmo porque, segundo alguns estudiosos, as medidas previstas pelo ECA para coibir a criminalidade praticada por menores seria suficiente, não sendo necessária a redução da imputabilidade penal.

A equiparação que muitas vezes é realizada entre o Brasil e outros países ignora especificidades sociais, culturais, políticas, econômicas e, de modo geral, o contexto do país no qual o adolescente está inserido. O que faz com que em um país como o Brasil, marcado pela desigualdade social, seja incabível que se cobre dos mais vulneráveis os ônus pelas mazelas sociais. Não pode deixar de ser apontado que é evidente que a fixação em 18 anos não se trata de algo exato, isto é, um momento específico e determinante no qual os jovens adquirem a capacidade e, a partir de então, saberão discernir o "certo" do "errado", mas sim se constituindo em um limite que compreendeu o legislador brasileiro como sendo razoável.

Nesse sentido, a aplicação de uma pena privativa de liberdade aos menores de 18 anos traz consequências para o encarceramento no Brasil, notadamente no 
que se refere a colocação de jovens juntos aos adultos, permitindo que compartilhem celas e recebam um igual tratamento da parte do Estado, vivenciando experiências semelhantes dentro do ambiente prisional. O que pode acarretar grandes prejuízos para os jovens, uma vez que mais do que reintegrá-los socialmente, poderia acabar por corrompê-los, tendo em vista que, infelizmente, são péssimas as condições de vida existentes em muitos presídios brasileiros (SANTOS, 2011).

Não obstante, nota-se na sociedade brasileira um constante clamor pela redução da imputabilidade penal. Isso se dá porque muitos de seus membros enxergam nessa medida uma solução mais rápida e conveniente para lidar com o problema dos menores infratores. Ao invés de uma aplicação mais efetiva de políticas públicas que possam auxiliar na questão e que se apresentam como um caminho possível na finalidade de resgatar da marginalidade social as crianças e adolescentes que nela se encontram inseridos, sendo benéficas e dignas para essa categoria especial de nossa sociedade (SANTOS, 2011).

Ainda sobre esse clamor social, embora não se refira a um dado jurídico, destaca-se em uma discussão como essa o papel dos meios de comunicação e dos discursos repressivos, uma vez que esses acabam por influenciar na maneira como a sociedade enxerga a imputabilidade penal. Como slogans e discursos de senso comum que levantam discursos de que a inimputabilidade é a porta para a impunidade ou de que os direitos humanos só deveriam ser aplicados para os "humanos direitos". Com isso, repercute entre muitos dos meios de comunicação brasileiros a ideia de que a nossa legislação precisa urgentemente ser modificada, com um reforço (endurecimento) na aplicação de sanções, de modo a intensificar as medidas punitivas (OLIVEIRA; SANTIBAÑEZ, 2017).

Em contrapartida, há aqueles que compreendem a redução da imputabilidade penal como uma medida legítima, sendo constitucionalmente possível, pois não se configuraria em uma cláusula pétrea. Além disso, apontam essa como uma medida necessária frente a atual situação dos menores no país. Nessa interpretação, os direitos e garantias individuais, contemplados no rol do art. 50, não trazem dentre eles qualquer dispositivo que trate acerca da imputabilidade penal, portanto, não 
podendo ser ela entendida enquanto cláusula pétrea, mas sim perfeitamente passível de Emenda Constitucional (CAVALCANTI, 2013).

Logo, a previsão do art. 228 da Constituição Federal seria apenas uma reprodução daquilo que o art. 27 do Código Penal já previa, reproduzindo um princípio válido no passado, mas que na realidade de hoje não mais se justificaria. Fazendo com que tal patamar, estabelecido aos 18 anos, seja referente a um outro contexto histórico-cultural vivido pelo país, bastante diferente do de hoje. Em que na nova realidade na qual nos encontramos inseridos o amadurecimento das crianças e adolescentes ocorre de forma mais rápida, dadas as diversas transformações sofridas nos últimos tempos (como o acesso à internet e os meios eletrônicos de comunicação e difusão de informações) (LINS; FIGUEIREDO FILHO; SILVA, 2016).

Até mesmo porque o próprio texto constitucional daria aos adolescentes uma responsabilidade muito grande e que comprovaria que aqueles que possuem tal idade são plenamente capazes de discernir acerca dos seus atos. Essa responsabilidade seria o direito ao voto, de maneira que o menor é visto como alguém que consegue influenciar na decisão sobre quem conduz a nação e ocupa o mais alto cargo do Poder Executivo brasileiro (voto nas eleições presidenciais), dentre outros cargos também muito importantes na democracia brasileira (CAVALCANTI, 2013).

Por isso, não seria coerente dar a eles tamanha responsabilidade, que claramente requer que tenham consciência sobre os seus atos, e, ao mesmo tempo, continuar a tratá-los como inimputáveis do ponto de vista criminal (CAVALCANTI, 2013). Assim, partindo-se do pressuposto de que é possível verificar a consciência política nos jovens é também possível que se verifique a sua consciência penal. Pois, se o próprio legislador-constituinte reconheceu lucidez e discernimento aos maiores de 16 anos neste tocante, esta deve ser aplicada para as suas condutas em desacordo à legislação penal, uma vez que a responsabilidade de voto é atribuída aqueles que possuem elevado grau de maturidade (BARBATO JÚNIOR, 2004).

De maneira que a conclusão lógica seria que tal responsabilidade fosse 
estendida à área penal, pois a maturidade reconhecida deveria alcançar todos os setores de suas vidas, sendo um contrassenso atitude diversa disso (CAVALCANTI, 2013). Nota-se, portanto, que há nisso uma analogia entre a maioridade política e a maioridade penal, em que a primeira é utilizada como forma de justificativa para a redução da segunda e aplicação de um tratamento igualitário para adultos e adolescentes (SARAIVA, 2002).

Ainda, no que se refere a questão da constitucionalidade da medida, caso a imputabilidade penal venha a ser reduzida, isso significa apenas uma mudança em seus termos, ou seja, naqueles que são por ela abrangidos, mas não em sua supressão, posto que ela ainda continuará a existir. Isso seria importante porque há uma compreensão segundo a qual a proibição trazida pelo texto constitucional se refere tão somente a essa questão. Sendo negada a tese que afirma existirem direitos e garantias individuais soltos em outros trechos da Constituição Federal, fazendo com que eles sejam também cláusulas pétreas e, assim, impossibilitados de ser objeto de emenda constitucional.

Embora o texto constitucional tenha expressamente adotado a doutrina da proteção integral, elevando o status constitucional que já era estabelecido pelo Código Penal, a inimputabilidade penal não poderia ser vista com a característica de uma cláusula pétrea, pois não se refere a um direito fundamental, haja vista não estar localizada no rol do art. 50. Acerca disso, as cláusulas pétreas representam uma construção que tem origem no direito alemão, sendo consequência de uma resposta ao formalismo sem conteúdo ético que possibilitou abusos de direitos protetores da pessoa humana, sem freios materiais aos atos abusivos de constituintes derivados (CAVALCANTI, 2013).

No Brasil, a teoria das cláusulas pétreas é marcada por uma imutabilidade sem ressalvas, não existindo qualquer mecanismo que possibilite a realização de mudanças a seu respeito, ainda que estas se dêem de forma extraordinária e que estejam amparadas por aceitação popular (como uma mudança muito desejada pela sociedade, exemplo do clamor social que envolve o debate da redução da imputabilidade penal ${ }^{11}$ ). Nesse cenário, o Supremo Tribunal Federal - STF, ao qual

\footnotetext{
${ }^{11}$ Notável que a deliberação acerca da redução da imputabilidade penal geralmente se torna mais Revista Auditorium, Rio de Janeiro, v. 25, n. 52, p. 36-61, jul./out. 2021
} 
foi atribuída a função de "guardião da Constituição", já reconheceu posteriormente a existência de direitos que, ainda que não contemplados no art. 50, seriam fundamentais, desde que possuam o mesmo perfil daqueles que lá se encontram ${ }^{12}$ (CAVALCANTI, 2013).

É válido destacar que em 1999 duas propostas de emenda constitucional para ter a imputabilidade penal reduzida receberam parecer favorável no intuito de alterar a previsão do art. 228 do texto constitucional e tornar possível a redução desta dos 18 para os 16 anos. Essas PECs de números 18 e 19, são, respectivamente, de autoria dos ex-senadores Romero Jucá e José Roberto Arruda. A primeira delas objetivava introduzir no país a aplicação de pena para os menores de 18 e maiores de 16 anos em determinados casos, como de crimes contra o patrimônio ou contra a vida que fossem praticados com violência ou grave ameaça à pessoa física, cessando a inimputabilidade nesses casos. Na segunda proposta, passaria a ser adotado o sistema tradicional do discernimento, aplicando a pena ao menor que apresentasse ter com esse agido (MINAHIM, 2004).

Como vimos, o ECA e o seu objetivo de garantir maior proteção para as crianças e adolescentes, amparando-os de quaisquer violações de direitos a que possam vir a ser submetidos, é utilizado como um norte para aqueles que se posicionam contrariamente à redução da imputabilidade penal. Não obstante, ao mesmo tempo, ele também acaba por servir de justificativa aos que adotam posicionamento diverso. Para esses, o Estatuto seria um código normativo ornamental, com metas que não seriam passíveis de realização, pois não correspondem à realidade brasileira, notadamente no que diz respeito a nossa realidade socioeconômica. Com isso, questiona-se a sua aplicabilidade diante da realidade dos menores no Brasil (BARBATO JÚNIOR, 2004).

forte quando um ato infracional grave é repercutido na mídia. Casos esses que colaboram para que a população brasileira discuta cada vez mais o assunto dentro de seu convívio pessoal, ganhando maior espaço nas discussões, sejam essas de modo formal ou informal, atingindo, inclusive, os meios de comunicação em massa.

12 Importante destacar que o problema aqui não se trata apenas do reconhecimento de que outros direitos, que não somente os do art. $5^{\circ}$, sejam compreendidos como garantias fundamentais, mas sim o debate se a inimputabilidade penal seria ou não um deles.

Revista Auditorium, Rio de Janeiro, v. 25, n. 52, p. 36-61, jul./out. 2021 


\section{CONSIDERAÇÕES FINAIS}

Esse artigo científico se propôs a verificar se a redução da imputabilidade penal violaria a Constituição Federal brasileira de 1988, bem como demais legislações nacionais, dentre as quais o Estatuto da Criança e do Adolescente, que comporta princípios como o do melhor interesse de crianças e adolescentes. Tendo isso em vista, foi levantado um problema de pesquisa a servir de guia para o desenvolvimento de toda a investigação, sendo esse o de questionar se no contexto brasileiro, e em observância do sistema constitucional que é vigente no país atualmente, uma eventual redução da imputabilidade penal seria possível, constituindo-se em uma prática revestida de legitimidade.

Procurando respondê-lo, foram traçados três objetivos específicos, os quais se concretizaram a cada sessão apresentada pela pesquisa (itens 1 ao 3) e nos permitiram adquirir o embasamento teórico (especialmente na teoria penal brasileira e na legislação nacional) julgado como necessário para tanto. Com isso, foi abordada a possibilidade de que seja a idade fixada para a imputabilidade penal no Brasil alterada, com uma leitura a seu respeito especialmente à luz do nosso texto constitucional. Ainda, foram descritos e analisados alguns dos principais argumentos que envolvem a discussão desse tema no cenário brasileiro, para que, a partir desses, pudéssemos verificar qual deles melhor responde a nossa problemática de pesquisa.

Dessa maneira, no transcorrer do desenvolvimento desta pesquisa foi possível analisarmos o surgimento da imputabilidade penal no ordenamento jurídico brasileiro, percorrendo-a desde a sua origem até alcançar a fixação hoje prevista em 18 anos. Isso nos permitiu compreendermos porque a possibilidade de que venha a ser reduzida causa tamanha repercussão dentre os teóricos brasileiros e, também, em nossa sociedade, ainda que no caso dessa última ela não se revista de um entendimento jurídico, que seja pautado em bases científicas.

Em um primeiro momento, analisamos a culpabilidade. Isso foi feito tendo em vista que dentre os elementos que a compõem encontra-se a imputabilidade, podendo, portanto, delinearmos melhor acerca desse conceito que é fundamental 
para a compreensão do tema abordado. Afinal, seria incompleta a pesquisa caso a realizássemos ignorando que a imputabilidade possui um conceito teórico e legislativo, pois compreender a seu respeito é essencial para podermos discutir a possibilidade de sua redução diante do ordenamento jurídico brasileiro.

Na sequência, na segunda parte deste artigo, foi realizada uma abordagem histórica da imputabilidade penal no Brasil. Partindo da primeira vez em que foi consolidada a sua previsão na legislação brasileira, até a atualidade, que proporciona tantos debates a seu respeito. Igualmente, com uma melhor explicitação do seu conceito, foram analisadas as suas características e os principais princípios com os quais ela se relaciona, dado que estes adentram a seara das discussões, servindo ora como justificativa para a sua redução, ora como motivação pela qual não poderia ser reduzida.

No último tópico desenvolvido pelo trabalho, foram descritos e analisados alguns dos argumentos que compõem os debates envolvendo a redução da imputabilidade penal, o que se realizou em dois sentidos: tanto os argumentos favoráveis, como os contrários a essa prática. De maneira que analisando cada um deles pudéssemos construir uma explicação para o nosso problema de pesquisa. Nesse momento, viu-se que um mesmo argumento pode ser utilizado por autores que adotam posições distintas. Exemplo do direito ao voto que é garantido para os cidadãos brasileiros a partir dos 16 anos, que tanto justifica que esses jovens já tenha adquirido a maturidade necessária para responder pelos atos ilícitos que eventualmente pratiquem, como para apontar que são em diferentes momentos da vida que se adquire as responsabilidades, posto que elas, inclusive, são de naturezas diferentes.

Diante de tudo isso, restou compreendido que essa é claramente uma discussão bastante polêmica, proporcionando debates os mais diversos, com distintos argumentos para a adoção de um posicionamento ou outro. Mas que, fundamentados por tudo aquilo que foi apresentado no seu desenvolvimento, nos posicionamos juntamente aqueles que entendem ser ilegítima uma medida nesse sentido, pois que a redução da imputabilidade penal implicaria em atitude inconstitucional, vez que tal garantia, para a presente pesquisa, revela-se uma 
garantia individual assegurada às crianças e adolescentes, aos quais deve sim ser dado um tratamento especial, de acordo com a sua condição específica de sujeitos em fase de desenvolvimento.

Com base em uma interpretação como essa, guiada por fundamentos teóricos, cumpre destacar que se acredita que o trabalho elaborado é importante para o enriquecimento do ambiente acadêmico, porque questões que geram controvérsias, como no caso do tema aqui apresentado, devem ser cada vez mais abordadas, buscando com isso respostas que ajudem a melhorar a sua compreensão e, igualmente, trazer soluções democráticas para as questões que ela envolve. Em relação a isso, entendemos que quanto a futuras pesquisas a serem realizadas sobre o tema, seria interessante que essas buscassem realizar uma leitura do tema em observância a realidade brasileira e de ser a fixação da imputabilidade penal aos 18 anos o resultado de toda evolução que o Brasil, e o mundo (conforme demonstram os tratados internacionais), passaram.

Ainda quanto ao problema que se buscou responder ao longo desta pesquisa, entende-se que não deve ser a imputabilidade penal reduzida, pois esta é um direito individual dos menores, não podendo Ihes ser retirada. São, assim, pessoas que ainda estão no início da formação de sua personalidade, que independentemente do discernimento que possam possuir, do desenvolvimento intelectual, escolaridade ou personalidade que possuam, não podem ser tratados como adultos, afinal, não o são. Por isso, se tem como compreensão que enxergar na redução da imputabilidade penal uma resposta aos problemas que o Brasil sofre com a criminalidade envolvendo jovens não é a solução mais adequada, tanto em termos democráticos (à luz da Constituição), nem em termos sociais.

O encarceramento, que em nosso país se dá em números cada vez maiores, não é a melhor medida a ser tomada. Para tanto, enxergamos nas políticas públicas um caminho muito mais eficaz, da mesma maneira que na educação e cuidado com os menores, colocando efetivamente em práticas as garantias que Ihes são asseguradas pelo texto constitucional. 


\section{REFERÊNCIAS}

BARBATO JÚNIOR, Roberto. Redução da maioridade penal: entre o direito e a opinião pública. Revista dos Tribunais, São Paulo, v. 93, n. 822, p. 429-443, abr. 2004. Disponível em: https://dspace.almg.gov.br/handle/11037/35266. Acesso em: 19 out. 2021.

BARRETO, Tobias. Menores e Loucos e fundamento do direito de punir. 2 ed. Rio de Janeiro: Paulo, Pongetti \& C., 1926. Disponível em: https://bibliotecadigital.stf.jus.br/xmlui/handle/123456789/776. Acesso em: 19 out. 2021.

BITENCOURT, Cezar Roberto. Tratado de Direito Penal: Parte Geral 1. 11. ed. São Paulo: Saraiva, 2007.

BONCHRISTIANO, Ana Cristina Ribeiro. A culpabilidade jurídico-penal. Revista de Julgados do Tribunal de Alçada Criminal do Estado de São Paulo, São Paulo, v. 19, n. 58, p. 13-23, jul./ago. 2002.

BRASIL. [Constituição (1988)]. Constituição da República Federativa do Brasil de 1988. Brasília, DF: Presidência da República, [2020]. Disponível em: http://www.planalto.gov.br/ccivil_03/constituicao/constituicao.htm. Acesso em: 27 jul. 2021.

BRASIL. Lei n 8.069, de 13 de julho de 1990. Dispõe sobre o Estatuto da Criança e do Adolescente e dá outras providências. Diário Oficial [da] República Federativa do Brasil, Brasília, DF, 16 jul. 1990. Disponível em: http://www.planalto.gov.br/ccivil_03/leis//8069.htm. Acesso em: 27 jul. 2021.

BRASIL. Decreto lei no 2.848, de 7 de dezembro de 1940. Código Penal. Diário Oficial da União, Rio de Janeiro, 31 dez. 1940. Disponível em: http://www.planalto.gov.br/ccivil_03/decreto-lei/del2848compilado.htm. Acesso em: 27 jul. 2021.

CAVALCANTI, Francisco de Queiroz Bezerra. Considerações acerca da redução da maioridade penal. Revista dos Tribunais Nordeste, São Paulo, v. 1, n. 2, p. 117-134, nov./dez. 2013. Disponível em: http://bdjur.stj.jus.br/dspace/handle/2011/83526. Acesso em: 14 out. 2021.

COSTA, Pedro Jorge. Culpabilidade na dosimetria da pena. Revista Brasileira de Ciências Criminais, São Paulo, v. 126, p. 109-132, dez. 2016. Disponível em: 
http://www.mpsp.mp.br/portal/page/portal/documentacao_e_divulgacao/doc_bibliot eca/bibli_servicos_produtos/bibli_boletim/bibli_bol_2006/RBCCrim_n.126.04.PDF. Acesso em: 18 out. 2021.

GRAU, Eros Roberto; TELLES JÚNIOR, Goffredo da Silva. A desnecessária e inconstitucional redução da maioridade penal. In: CRISÓSTOMO, Eliana Cristina R. Taveira et al (Org.). A razão da idade: Mitos e Verdades. Coleção Garantia de Direitos. Série Subsídios. Tomo VII. Brasília: MJ; SEDH; DCA, 2001.

LIBERATI, Wilson Donizeti. Processo Penal Juvenil: a garantia da legalidade na execução de medida socioeducativa. São Paulo: Malheiros, 2006.

LINS, Rodrigo; FIGUEIREDO FILHO, Dalson; SILVA, Lucas. A redução da maioridade penal diminui a violência? Evidências de um estudo comparado. Opinião Pública, Campinas, v. 22, n. 1, p. 118-139, jan./abr. 2016. Disponível em: https://doi.org/10.1590/1807-0191201622118. Acesso em: 28 jul. 2021.

LOBO, Silvana Lourenço. A idade no Direito Penal Brasileiro: Da menoridade. Belo Horizonte: Mandamentos; Universidade FUMEC; FHC, 2008.

MARANHÃO, Douglas Bonaldi; GOMES, Luís Roberto. Menoridade Penal. Revista de Ciências Penais: Revista da Associação Brasileira de Professores de Ciências Penais, São Paulo, v. 4, n. 7, p. 146-181, jul./dez. 2007. Disponível em: http://dbmadvocacia.com.br/media/uploads/artigos/ABPCP_V._7.pdf. Acesso em: 28 jul. 2021.

MASSA, Patrícia Helena. A menoridade penal no direito brasileiro. Revista Brasileira de Ciências Criminais, São Paulo, v. 1, n. 4, p. 126-132, out./dez. 1993.

MINAHIM, Maria Auxiliadora. Novos limites para a maioridade penal: um tema recorrente. Revista de Ciências Penais: Revista da Associação Brasileira de Professores de Ciências Penais, São Paulo, v. 1, 2004.

OLIVEIRA, Arlindo Severino Teixeira de. Culpabilidade como limite da pena: requisito do sistema político-criminal garantista. Revista dos Tribunais, São Paulo, v. 103, n. 944, p. 187-201, jun. 2014. Disponível em: https://dspace.almg.gov.br/handle/11037/21621. Acesso em: 18 out. 2021.

OLIVEIRA, Dijaci David de; SANTIBAÑEZ, Dione Antônio Carvalho de Souza. Segurança ou criminalização dos adolescentes: confrontando o discurso da redução da maioridade penal no Brasil. Revista Espacio Abierto: Cuaderno Venezolano de Revista Auditorium, Rio de Janeiro, v. 25, n. 52, p. 36-61, jul./out. 2021 
Sociología. Caracas, v. 26, n. 1, p. 109-120, enero/marzo 2017. Disponível em: https://dialnet.unirioja.es/servlet/articulo?codigo=5910478. Acesso em: 19 out. 2021.

SANTOS, Juarez Cirino dos. Direito Penal: Parte Geral. 5 ed. Florianópolis: Conceito Editorial, 2012.

SANTOS, Richardy Videnov Alves dos. A Inoportuna redução da maioridade penal: uma análise de fatos, valores e normas. Revista de Filosofia do Direito, do Estado e da Sociedade, Natal, v. 2, n. 1, p. 214-234, jan./jun. 2011. Disponível em: http://www.revistafides.ufrn.br/index.php/br/article/view/72/77. Acesso em: 28 jul. 2021.

SARAIVA, João Batista Costa. A idade e as razões: não ao rebaixamento da imputabilidade penal. Revista Brasileira de Ciências Criminais: Cidade. v. 18, n.4, p. 98-107, 1997. Disponível em:

http://www.mpsp.mp.br/portal/page/portal/documentacao_e_divulgacao/doc_bibliot eca/bibli_servicos_produtos/bibli_boletim/bibli_bol_2006/SRC\%2004_98.pdf. Acesso em: 18 out. 2021.

\section{João Batista Costa. Direito Penal Juvenil - Adolescente e ato}

infracional: garantias processuais e medidas socioeducativas. 2. ed. rev. e ampl. com a íntegra da proposta de Lei de diretrizes socioeducativas. Porto Alegre: Livraria do Advogado, 2002.

SPOSATO, Karyna Batista; MATOS, Êmille Laís de Oliveira. Impedimentos constitucionais à redução da maioridade penal no Brasil. Revista Brasileira de Estudos Constitucionais, Belo Horizonte, v. 7, n. 25, p. 33-52, jan./abr. 2013. Disponível em: https://dspace.almg.gov.br/handle/11037/6396. Acesso em: 18 out. 2021. 